\title{
Effects of Glucose-Induced Insulin Secretion on Ventricular Repolarization in Patients With Congenital Long QT Syndrome
}

\author{
Mitsuhiro Nishizaki, MD; Takashi Ashikaga, MD; Noriyoshi Yamawake, MD; \\ Hiroyuki Fujii, MD; Masataka Arita, MD; Naokata Sumitomo, MD*; \\ Harumizu Sakurada, MD**; Masayasu Hiraoka, MD ${ }^{\dagger}$
}

\begin{abstract}
To assess the role of insulin in ventricular repolarization in patients with congenital long QT syndrome (LQTS), an oral glucose tolerance (OGT) test was performed in 11 patients with LQTS and in 11 control cases without QT prolongation. Plasma glucose, potassium level and the immunoreactive insulin concentration (IRI) were measured, and the QT interval and T wave morphology on 12-lead ECG were analyzed during fasting and after glucose load. The LQTS group had a higher incidence of changes in T wave morphology, such as biphasic, bifid or notched $\mathrm{T}$ wave, after glucose load than the control group (11 of 11 patients [100\%] vs 0 of 11 [0\%]; $\mathrm{p}<0.00001$ ). The $\mathrm{T}$ wave changes returned to baseline at $180 \mathrm{~min}$ after glucose load in 7 patients. The maximal QT interval and QT dispersion increased significantly and returned to baseline level in response to IRI after glucose load in LQTS, whereas the QT interval was unaffected in the control group. After glucose load, ventricular arrhythmias and T wave alternans were observed in 3 and 1 patients with LQTS, respectively, but none in the control group. The findings suggest that glucose-induced insulin secretion plays a role in inducing abnormalities and inhomogeneity of ventricular repolarization in patients with LQTS. (Circ J 2002; 66: 35-40)
\end{abstract}

Key Words: Insulin; Long QT syndrome; QT dispersion; Ventricular arrhythmia; Ventricular repolarization

$\mathbf{I}$ nsulin modulate ion transport mechanisms in cardiac and skeletal muscles, but has little influence on membrane potential other than hyperpolarization of the resting potential! A recent report suggested that insulin stimulates the L-type calcium current in isolated rat ventricular myocytes in a dose-dependent manner, and we recently reported that QT dispersion was associated with an increased plasma insulin level during an oral glucose tolerance (OGT) test in healthy volunteers? However, it is not known whether glucose-induced insulin secretion plays a functional role in abnormal ventricular repolarization in the human heart.

Congenital long QT syndrome (LQTS) caused by mutation of the cardiac potassium- and sodium-channel genes and their associated subunits has distinct ECG abnormalities of ventricular repolarization. The abnormal ST-T wave forms are variously affected by changes in physiological factors including serum electrolyte and catecholamine levels, which may underlie different phenotypes and timedependent fluctuations of the ST-T changes in these patients. ${ }^{4-13}$ However, there has not been an exploration of

(Received July 24, 2001; revised manuscript received September 18, 2001; accepted October 1, 2001)

Department of Cardiology, Yokohama Minami Kyosai Hospital, *Department of Pediatric Medicine, Nihon University, School of Medicine, Tokyo, **Department of Cardiology, Tokyo Metropolitan Hiroo Hospital, Tokyo and Department of Cardiovascular Diseases, Medical Research Institute, Tokyo Medical and Dental University, Tokyo, Japan

Mailing address: Mitsuhiro Nishizaki, MD, Department of Cardiology, Yokohama Minami Kyosai Hospital, 500 Mutsuura, Kanazawaku, Yokohama, Kanagawa 236-0016, Japan. E-mail: nisizaki@yhb.att. ne.jp the effects of plasma insulin level after food intake or glucose load on ventricular repolarization in patients with congenital LQTS. We hypothesized that insulin might exert dose-dependent effects on ventricular repolarization in the human heart and that patients with congenital LQTS would be more sensitive to the insulin action than age-matched control healthy subjects with a normal QT interval. The present study was designed to investigate this hypothesis.

\section{Methods}

\section{Study Patients}

The study included 11 patients with congenital LQTS (4 men, 7 women; mean age, $25 \pm 9$ years, range 12-44) and 11 healthy age-matched volunteers with normal QT interval as the control group (5 men, 6 women; mean age, $27 \pm 8$ years, range 17-44). All 11 patients with congenital LQTS had a documented QTc interval (corrected QT interval with a modification of Bazzett's formula ${ }^{14}$ ) greater than $480 \mathrm{~ms}$ $(498 \pm 40 \mathrm{~ms})$ on 12 -lead ECG before receiving medication. Ten patients had a history of stress-induced syncope, and one had a history of cardiac arrest. Torsades de pointes was documented in 8 patients: it was familial in 7 and sporadic in 4 patients.

Three patients with congenital LQTS were taking propranolol, one was taking propranolol and mexiletine, and 7 were not receiving any medication at the time of OGT test. The control group had a mean QT interval of $401 \pm 27 \mathrm{~ms}$. Both groups had normal results on physical examination and no overt diabetes mellitus, renal disease or endocrine disorders. Excluded were subjects with a systolic blood pressure greater than $140 \mathrm{mmHg}$, diastolic blood pressure greater than $85 \mathrm{mmHg}$, total cholesterol greater than 12.2 
Table 1 Clinical Characteristics of Patients With Long QT Syndrome

\begin{tabular}{|c|c|c|c|c|c|c|}
\hline \multirow{2}{*}{ Patient no. } & \multirow{2}{*}{$\begin{array}{c}\text { Age (years) } \\
\text { /sex }\end{array}$} & \multicolumn{2}{|c|}{ Symptoms } & \multirow{2}{*}{$\begin{array}{l}\text { Family } \\
\text { history }\end{array}$} & \multirow{2}{*}{$\begin{array}{l}\text { Diabetes } \\
\text { mellitus }\end{array}$} & \multirow{2}{*}{ Medication } \\
\hline & & Syncope & $T d p$ & & & \\
\hline 1 & $12 / F$ & + & + & + & - & - \\
\hline 2 & $35 / F$ & + & + & + & - & Propranolol \\
\hline 3 & $26 / F$ & + & + & - & - & Propranolol \\
\hline 4 & $20 / M$ & + & - & + & - & - \\
\hline 5 & $20 / M$ & + & + & + & - & $\begin{array}{c}\text { Propranolol } \\
\text { Mexiletine }\end{array}$ \\
\hline 6 & $21 / F$ & + & - & - & - & - \\
\hline 7 & $15 / F$ & + & - & + & - & - \\
\hline 8 & $28 / F$ & + & + & - & - & Propranolol \\
\hline 9 & $22 / M$ & + & + & + & - & - \\
\hline 10 & $44 / F$ & + & + & + & - & - \\
\hline 11 & $33 / M$ & + & + & - & - & - \\
\hline
\end{tabular}

Tdp, torsade de pointes.

Table 2 Results of the Oral Glucose Tolerance Test

\begin{tabular}{|c|c|c|c|}
\hline & Long $\underset{(n=11)}{Q T \text { syndrome }}$ & $\begin{array}{c}\text { Control group } \\
(n=11)\end{array}$ & $p$ value \\
\hline \multicolumn{4}{|c|}{ Potassium level $(\mathrm{mmol} / \mathrm{L})$} \\
\hline Fasting & $3.9 \pm 0.3$ & $4 \pm 0.2$ & $N S$ \\
\hline $30 \mathrm{~min}$ & $4.0 \pm 0.3$ & $4.0 \pm 0.3$ & $N S$ \\
\hline $60 \mathrm{~min}$ & $3.9 \pm 0.3$ & $3.9 \pm 0.3$ & $N S$ \\
\hline $120 \mathrm{~min}$ & $3.9 \pm 0.2$ & $3.9 \pm 0.3$ & $N S$ \\
\hline $180 \mathrm{~min}$ & $4 \pm 0.2$ & $4 \pm 0.2$ & $N S$ \\
\hline \multicolumn{4}{|c|}{ Plasma glucose $(\mathrm{mmol} / \mathrm{L})$} \\
\hline Fasting & $4.9 \pm 0.4$ & $5.1 \pm 0.5$ & $N S$ \\
\hline $30 \mathrm{~min}$ & $7.9 \pm 1.9 * *$ & $8.4 \pm 1.1 * *$ & $N S$ \\
\hline $60 \mathrm{~min}$ & $8.2 \pm 2.7 * *$ & $9.1 \pm 1.6^{* *}$ & $N S$ \\
\hline $120 \min$ & $7.0 \pm 1.5 * *$ & $7.4 \pm 1.0 * *$ & $N S$ \\
\hline $180 \min$ & $5.3 \pm 1.0$ & $5.6 \pm 1.3$ & $N S$ \\
\hline \multicolumn{4}{|l|}{ IRI $(\mathrm{pmol} / \mathrm{L})$} \\
\hline Fasting & $42 \pm 30$ & $48 \pm 30$ & $N S$ \\
\hline $30 \min$ & $384 \pm 462 *$ & $312 \pm 198 * *$ & $N S$ \\
\hline $60 \mathrm{~min}$ & $306 \pm 228 * *$ & $366 \pm 174 * *$ & $N S$ \\
\hline $120 \min$ & $246 \pm 132 * *$ & $312 \pm 138 * *$ & $N S$ \\
\hline $180 \mathrm{~min}$ & $90 \pm 60$ & $150 \pm 120 *$ & $N S$ \\
\hline
\end{tabular}

${ }^{*} p<0.05$ vs Fasting, ${ }^{* *} p<0.01$ vs Fasting. IRI, plasma immunoreactive insulin concentration.

$\mathrm{mmol} / \mathrm{L}(220 \mathrm{mg} / \mathrm{dl})$, triglyceride greater than $8.3 \mathrm{mmol} / \mathrm{L}$ $(150 \mathrm{mg} / \mathrm{dl})$, a high-density lipoprotein cholesterol less than $2.2 \mathrm{mmol} / \mathrm{L}(40 \mathrm{mg} / \mathrm{dl})$ or a body mass index greater than $25 \mathrm{~kg} / \mathrm{m}^{2}$. The clinical characteristics of the patients with congenital LQTS are presented in Table 1.

The study protocol was approved by the Ethics Committee of the institution and written informed consent was obtained from all subjects.

\section{Glucose Tolerance Test}

The OGT test was done according to WHO guidelines. All 22 participants followed their normal diet and restricted performance of heavy physical exercise, smoking and caffeine for 3 days before the test. After an overnight fast, each drank a glucose solution $(75 \mathrm{~g}$ in $200 \mathrm{ml}$ of water) at $09.00 \mathrm{~h}$. Venous blood samples were taken for measurement of plasma glucose $(\mathrm{mmol} / \mathrm{L})$, plasma immunoreactive insulin concentration (IRI: pmol/L) and potassium level $(\mathrm{mg} / \mathrm{dl}$ ) during fasting and at 30,60,120, and $180 \mathrm{~min}$ after the glucose load? Plasma samples were stored at $-20^{\circ} \mathrm{C}$ and each sample was assayed for glucose and IRI. Plasma glucose was determined with an autoanalyser using a glucose oxidase method. IRI was assessed by radioimmunoassay using an antihuman insulin antibody.
$T$ Wave Morphology, QT Interval and QT Dispersion on 12-Lead ECG

The QT interval and QRS duration were measured in all leads of a 12-lead ECG recorded at a paper speed of 50 $\mathrm{mm} / \mathrm{s}$ for 2 consecutive cardiac cycles during fasting and at 30, 60, 120 and $180 \mathrm{~min}$ after glucose load? The QT (U) interval was defined as the time between the beginning of the QRS complex and the point at which the line of maximal downslope of the $\mathrm{T}$ wave [or the late component of the $\mathrm{T}(\mathrm{U})$ complex, if present] crossed the baseline before the isoelectric UP interval!5 None of the 11 healthy volunteers had a $U$ wave superimposed on the terminal portion of $\mathrm{T}$ wave. If the $\mathrm{T}$ wave could not be reliably determined or if it had a very low amplitude, QT measurements were not obtained, and those leads were excluded from the analysis. The QT interval was measurable in 9-12 leads (mean, $11 \pm 1$ leads) in each subject. The mean QT interval was calculated as the average of all measurable leads.

QT dispersion, defined as the difference between the maximum and minimum QT intervals, was determined by previously described methods? Measurements were obtained during fasting and at $30,60,120$, and $180 \mathrm{~min}$ after the glucose load. Two independent experienced observers who were unaware of the clinical data performed the analysis. 
Table 3 T Wave Changes, QT Intervals and QT Dispersion During the Oral Glucose Tolerance Test

\begin{tabular}{|c|c|c|c|}
\hline & $\begin{array}{c}\text { Long } \underset{Q T \text { syndrome }}{(n=11)} \\
\text { (n) }\end{array}$ & $\begin{array}{c}\text { Control group } \\
(n=11)\end{array}$ & $p$ value \\
\hline $\begin{array}{l}\text { Changes in T wave } \\
\text { morphology (yes/no) }\end{array}$ & $11 / 0$ & $0 / 11$ & $<0.00001$ \\
\hline \multicolumn{4}{|l|}{ QT maximum (ms) } \\
\hline Fasting & $587 \pm 73$ & $422 \pm 21$ & $<0.0001$ \\
\hline $30 \mathrm{~min}$ & $627 \pm 58 *$ & $424 \pm 25$ & $<0.0000001$ \\
\hline $60 \mathrm{~min}$ & $617 \pm 76^{*}$ & $423 \pm 33$ & $<0.00001$ \\
\hline $120 \min$ & $616 \pm 105$ & $420 \pm 29$ & $<0.0001$ \\
\hline $180 \mathrm{~min}$ & $586 \pm 65$ & $420 \pm 29$ & $<0.00001$ \\
\hline \multicolumn{4}{|l|}{$Q T$ minimum (ms) } \\
\hline Fasting & $451 \pm 69$ & $389 \pm 24$ & $<0.05$ \\
\hline $30 \mathrm{~min}$ & $446 \pm 63$ & $386 \pm 23$ & $<0.05$ \\
\hline $60 \min$ & $445 \pm 57$ & $382 \pm 25$ & $<0.01$ \\
\hline $120 \mathrm{~min}$ & $450 \pm 63$ & $383 \pm 31$ & $<0.01$ \\
\hline $180 \mathrm{~min}$ & $456 \pm 59$ & $381 \pm 29$ & $<0.01$ \\
\hline \multicolumn{4}{|l|}{ QT dispersion (ms) } \\
\hline Fasting & $135 \pm 65$ & $33 \pm 7$ & $<0.001$ \\
\hline $30 \mathrm{~min}$ & $179 \pm 64 * *$ & $38 \pm 16$ & $<0.0001$ \\
\hline $60 \mathrm{~min}$ & $171 \pm 53^{*}$ & $40 \pm 22$ & $<0.00001$ \\
\hline $120 \min$ & $164 \pm 71$ & $37 \pm 8$ & $<0.001$ \\
\hline $180 \mathrm{~min}$ & $130 \pm 63$ & $30 \pm 6$ & $<0.001$ \\
\hline
\end{tabular}

$*_{p}<0.05$ vs Fasting, ${ }^{* *} p<0.01$ vs Fasting.
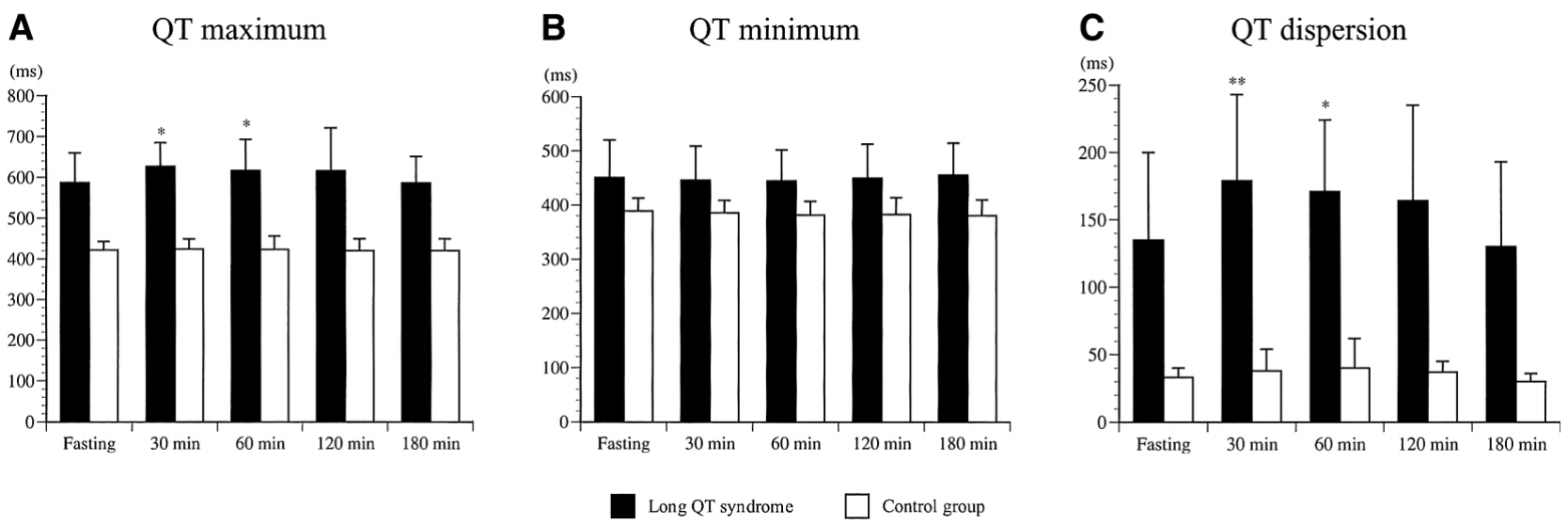

Fig 1. Changes in the QT interval and QT dispersion during the oral glucose tolerance test (A) The maximal QT interval in the long QT syndrome and control groups. The maximal QT intervals at 30 and $60 \mathrm{~min}$ after glucose load were significantly increased compared with the fasting value in patients with long QT syndrome. * ${ }^{\mathrm{p}}<0.05$ vs Fasting. (B) The minimal QT interval in the long QT syndrome and control groups. The minimal QT interval did not change significantly after glucose load in the 2 groups. (C) The QT dispersion in the long QT syndrome and control groups. The QT dispersion at 30 and $60 \mathrm{~min}$ after the glucose load was significantly increased and returned to the fasting level in patients with long QT syndrome. $* \mathrm{p}<0.05$ vs Fasting, ${ }^{*} \mathrm{p}<0.01$ vs Fasting. Data are mean \pm SD.

Linear regression analysis yielded minimal intraobserver $(\mathrm{r}=0.95, \mathrm{p}<0.0001)$ and interobserver $(\mathrm{r}=0.94, \mathrm{p}<0.0001)$ variations. A changes in $\mathrm{T}$ wave morphology was defined as a distinctly visible alteration of $\mathrm{T}$ wave morphology, such as broad-based, biphasic, bifid or notched $\mathrm{T}$ waves and macroscopic $\mathrm{T}$ wave alternans! ${ }^{12,13,16-19}$

\section{Statistical Analysis}

Data are expressed as the mean value \pm SD. The 2-tailed unpaired Student's $t$ test was used for comparison of group mean values expressed as continuous variables. The chisquare test was used to evaluate differences in categorical variables between the 2 groups. Multiple comparisons of continuous variables were performed by ANOVA coupled with Scheffe's test. A p value $<0.05$ was considered significant.

\section{Results}

Responses of Potassium, Glucose and Insulin During the OGT Test (Table 2)

Impaired glucose tolerance was detected in 2 of 11 patients with congenital LQTS and in 2 of 11 control subjects. Diabetes mellitus was not documented in either group. Plasma glucose and IRI after glucose load were significantly higher than during fasting in each group, but there were no significant differences between the 2 groups in potassium level, plasma glucose and IRI during fasting and after glucose load.

\section{Heart Rate, QRS Duration and QT Interval During OGT Test}

There was no significant difference between the 2 groups in heart rate (HR) during fasting and after glucose load. In 
A

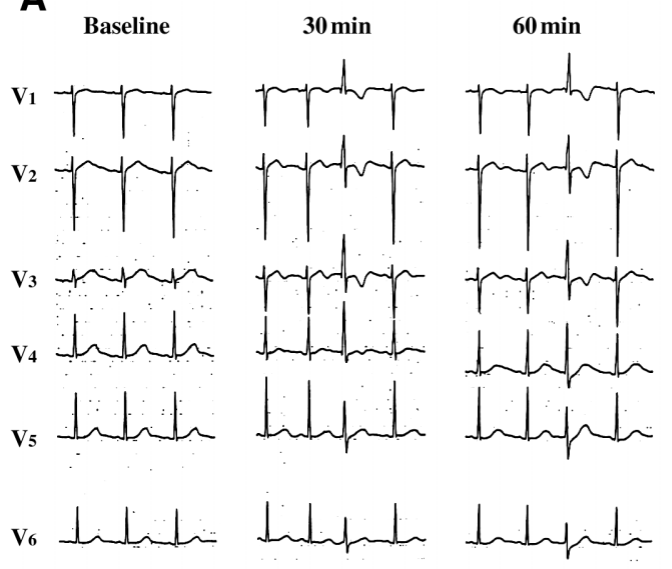

B

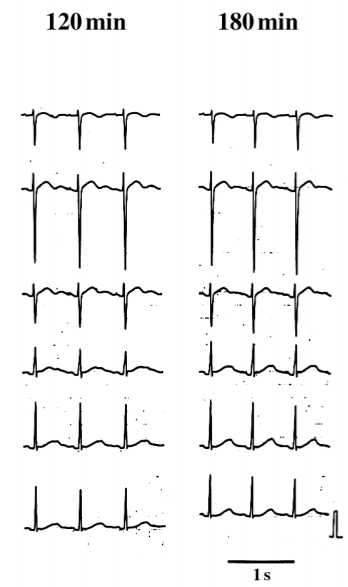

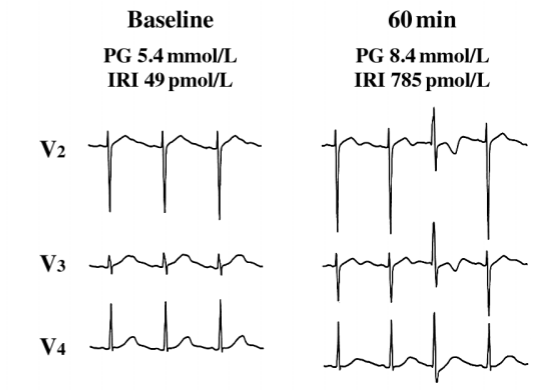

PG $8.4 \mathrm{mmol} / \mathrm{L}$ IRI $785 \mathrm{pmol} / \mathrm{L}$

Fig 2. ECG from patient 1 during oral glucose tolerance test before receiving oral $\beta$-blocker. (A) $T$ wave morphologies in leads $V_{1-4}$ changed distinctively after glucose load and ventricular arrhythmias were observed at 30 and $60 \mathrm{~min}$. (B) Enlarged ECGs showed bifid T wave changes in leads $V_{2}$ and $V_{3}$ at 60 min after glucose load with increased IRI. PG, plasma glucose; IRI, immunoreactive insulin concentration.

A

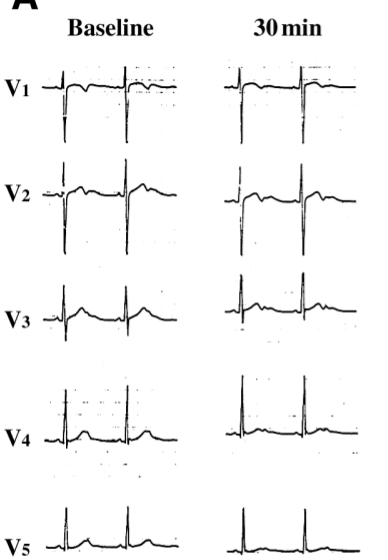

V6 Jidn
$60 \mathrm{~min}$
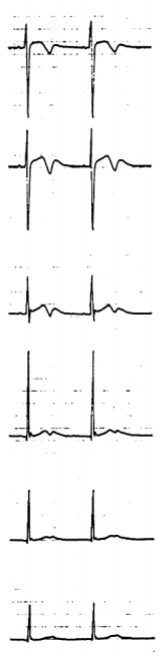

$120 \mathrm{~min}$
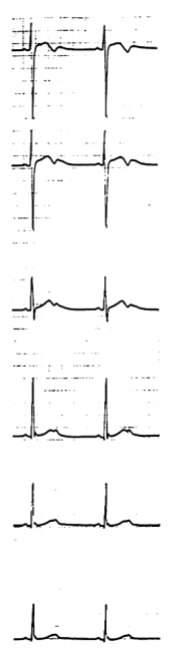

B
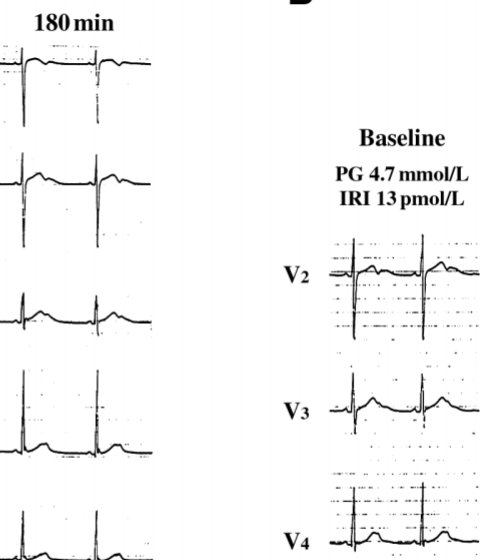

$60 \mathrm{~min}$

PG 7.0 $\mathrm{mmol} / \mathrm{L}$ IRI $301 \mathrm{pmol} / \mathrm{L}$
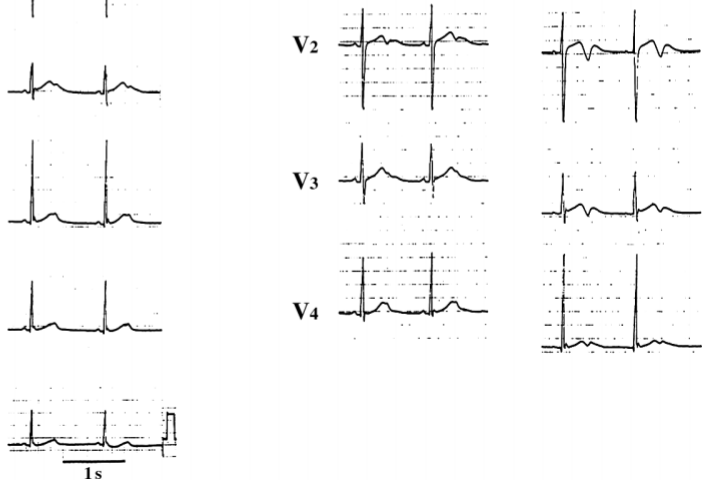

Fig 3. ECG from patient 5 after oral administration of $\beta$-blocker and mexiletine during oral glucose tolerance test. (A) $\mathrm{T}$ wave morphologies in leads $V_{1-6}$ changed distinctively after glucose load and returned to baseline at $180 \mathrm{~min}$. (B) Enlarged ECGs showed biphasic and bifid T wave changes in leads $\mathrm{V}_{2}$ and $\mathrm{V}_{4}$ at $60 \mathrm{~min}$ after glucose load with remarkable increased IRI.

patients with LQTS, the fasting HR was $60 \pm 10$ beats/min, and at $30,60,120$ and $180 \mathrm{~min}$ after glucose load, it was $61 \pm 8,61 \pm 8,59 \pm 10$ and $59 \pm 10$ beats/min, respectively. In control subjects, fasting HR was $61 \pm 8$ beats/min and at 30 , 60,120 and $180 \mathrm{~min}$ after glucose load, it was $61 \pm 6,62 \pm 6$, $62 \pm 6$ and $60 \pm 6$ beats $/ \mathrm{min}$, respectively.

There was no significant difference in the mean QRS duration during fasting and after glucose load between the LQTS and control groups. In LQTS, the QRS duration during fasting was $80 \pm 17 \mathrm{~ms}$ and at $30,60,120$ and $180 \mathrm{~min}$ after glucose load, it was $80 \pm 18,80 \pm 17,80 \pm 19$ and $80 \pm 17$ $\mathrm{ms}$, respectively. In the control group, the QRS duration during fasting was $80 \pm 15 \mathrm{~ms}$, and at $30,60,120$ and 180 min after glucose load, it was $80 \pm 17,80 \pm 16,80 \pm 16$ and $80 \pm 15 \mathrm{~ms}$, respectively. The maximal and minimal QT intervals during fasting and after glucose load were significantly higher in the LQTS group. The maximal QT interval increased significantly after glucose load with recovery to the fasting level after $180 \mathrm{~min}$, but the minimal QT interval was unaffected in the LQTS group (Table 3). Maximal and minimal QT intervals did not change significantly during the OGT test in the control group (Fig 1A,B).

\section{$T$ Wave Change and QT Dispersion During OGT Test}

The LQTS group had a higher incidence of changes in $\mathrm{T}$ wave morphology after glucose load (11 of 11 patients [100\%]) than the control group (0 of 11 [0\%]; $\mathrm{p}<0.0001)$. Biphasic or bifid (notched) $\mathrm{T}$ wave changes became visible after glucose load in all patients with LQTS (Figs 2,3). Both biphasic and bifid $\mathrm{T}$ wave changes were observed after glucose load in 4 of the 11 LQTS patients and a broadbased $\mathrm{T}$ wave developed after glucose load in 8 patients. The $\mathrm{T}$ wave changes returned to the fasting level $180 \mathrm{~min}$ after glucose load in 7 of 11 patients (Fig 3). Isolated prema- 

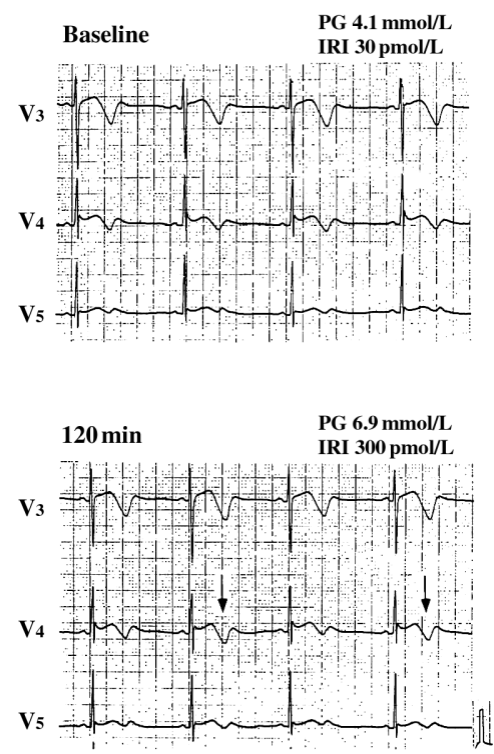

Fig 4. ECG from patient 3 during fasting and at $120 \mathrm{~min}$ after glucose load during oral glucose tolerance test. $\mathrm{T}$ wave alternans (arrows) was observed in leads $\mathrm{V}_{3}$ and $\mathrm{V}_{4}$ at 120 min after glucose load. PG, plasma glucose; IRI, immunoreactive insulin concentration.

ture ventricular contractions and T-wave alternans were observed after glucose load in 3 and 1 patients, respectively (Figs 2,4). The QT dispersion during fasting and after glucose load was significantly greater in the LQTS group than in the controls. It increased significantly after glucose load and returned to fasting level at $180 \mathrm{~min}$, whereas in the control group there was no significant change in this parameter (Table 3, Fig 1C). In the LQTS group, there was no significant difference between the patients with and without medication in QT dispersion during fasting and after glucose load.

\section{Discussion}

We evaluated the relation between plasma insulin level during an OGT test and ventricular repolarization abnormalities in patients with congenital LQTS. T wave morphology changed distinctively with increased IRI after glucose load in all cases in the LQTS group, but not in control group. QT dispersion was also increased after glucose load in patients with LQTS compared with the control group. QT dispersion reflects the regional variation in ventricular repolarization, which provides an electrophysiologic substrate for arrhythmias. ${ }^{20-23}$ These findings suggest that glucose-induced insulin secretion is one of the factors that induces or aggravates abnormalities of repolarization in patients with LQTS, which may increase their susceptibility to ventricular arrhythmias.

\section{Effect of Glucose-Induced Insulin Secretion on \\ Ventricular Repolarization Abnormalities}

In our previous study, an increased level of IRI correlated with QT dispersion in 20 middle-aged volunteers, but no relation was found between QT dispersion and plasma glucose level. That result suggested that high plasma insulin levels might provoke a widening of regional differences in repolarization of the ventricle. In the present study, we selected age-matched control subjects and the insulin responses to the OGT test showed similar values in both groups. Only the LQTS group responded with increased QT dispersion during the OGT test, indicating high sensitivity to insulin in ventricular repolarization.

Not only QT dispersion, but also T wave morphologies were affected by glucose-induced insulin secretion in the LQTS group, and the changes returned to the baseline in most cases after $180 \mathrm{~min}$ with a concomitant return of the IRI level. A widened or bifurcated $\mathrm{T}$ wave, and prolonged QT intervals similar to the present observations have been observed under simulated long QT conditions created by opposing voltage gradients between the epicardium and the $\mathrm{M}$-cell region, and the endocardium and the M-cell region in a canine wedge preparation. ${ }^{6,18,19,23}$ It is not known how insulin affects the different components of the repolarizing currents among the cells in the epi- and endocardium and M-region, where subtle differences in the $\mathrm{K}^{+}$and $\mathrm{Na}^{+}$ currents are present. Recently, Aulbach et $\mathrm{al}^{2}$ have shown that insulin stimulates the L-type $\mathrm{Ca}^{2+}$ current in isolated rat ventricular myocytes in a dose-dependent manner, although the effects are not so remarkable. If the stimulant action of the L-type $\mathrm{Ca}^{2+}$ current by insulin is also observed in human ventricle in the clinical situation, the most pronounced effect would be expected to develop in the Mcell region where opposing outward currents are less than in the other 2 regions. In accordance with this expectation, the maximal QT intervals in the present patients with LQTS were prolonged with increased IRI, but the minimal QT intervals were unchanged. Nevertheless, the maximal QT intervals in the controls did not change significantly. However, the number of control subjects in this study was less than in our previous study in which impaired glucose tolerance was detected in 11 of 20 middle-aged volunteers. The younger aged control group in the present study had low insulin levels within a narrow range compared with the middle-aged volunteers in our previous study, 3 so the different responses to insulin between 2 control groups might caused by dose-dependent effects of insulin on the maximal QT interval and QT dispersion. Insulin has been shown to cause hyperpolarization of the membrane potential through activation of the $\mathrm{Na}^{+}-\mathrm{K}^{+}$pump, ${ }^{24-26}$ which could also produce a high $\mathrm{K}^{+}$gradient across the cell membrane with depletion of $\mathrm{K}^{+}$from the narrow extracellular space. Although the serum $\mathrm{K}^{+}$concentrations were unchanged after glucose load in both groups in the present study, the possibility that an increased $\mathrm{K}^{+}$gradient could affect the repolarization process differently among the 3 regions of the ventricular wall cannot be excluded, and might contribute to the abnormalities observed in LQTS. The cellular basis for these abnormalities produced by insulin needs to be further explored.

\section{Clinical Implications}

Molecular identification of the gene responsible for QT prolongation has disclosed a wide spectrum of clinical manifestations ?-12 $^{-12}$ Some sporadic cases of nonfamilial LQTS have exhibited a distinct gene $\operatorname{defect}^{27}$ and some cases of drug-induced LQTS, which is believed to be an acquired form, have a subtle genetic abnormality that only manifests as QT prolongation with the taking of drugs.28 Therefore, the importance of genetic screening for patients with concealed QT prolongation is now widely recognized, although it is still a research-oriented examination and not available to every patient on a clinical basis.

On the other hand, the OGT test is an easy and widely 
used method. with which a high incidence of repolarization abnormalities can easily be detected and thus provide a good provocation test for selecting those patients requiring genetic screening.

The QT prolongation and ST-T changes in patients with LQTS may fluctuate from time to time and can not be predicted because of the multiple factors influencing ventricular repolarization and the different gene defects with their variable phenotypic expressions. High plasma insulin levels are another factor that aggravate ST-T changes and QT dispersion, but there have not been any reports of increased incidence and development of torsades de pointes after food intake. Further careful follow-up in a large-scale study is necessary to clarify the clinical significance of the insulin effects observed in the present study.

\section{Study Limitations}

The genetic defects in LQTS involved in 2 different $\mathrm{K}^{+}$ and $\mathrm{Na}^{+}$channels,-7 creating different ionic bases of the QT prolongation. The genetic basis of the present patients was not known except for 2 cases that had a mutation in HERG (LQT2: patients 5 and 8). Although none of other 9 cases showed the T-wave morphology typical of LQT3 according to Moss et al29 it was not known whether they presented abnormalities in the rapid $(\mathrm{Ikr})$ or slow $(\mathrm{Iks})$ components of the delayed rectifier $\mathrm{K}^{+}$or $\mathrm{Na}^{+}$channels, and whether the changes observed were specific generelated phenomena or not. Therefore, the relationship between repolarization abnormalities occurring during the OGT test and the genotype of patients with LQTS remains to be evaluated.

\section{Conclusions}

A high insulin level after glucose load in patients with LQTS was associated with further QT prolongation, increased QT dispersion and changes in T wave morphology. Glucose-induced insulin secretion may plays a role in the abnormalities and inhomogeneity of repolarization, provoking increased susceptibility to ventricular arrhythmias. Further study is required to clarify its clinical significance and the ionic mechanisms.

\section{References}

1. Moore RD. Effects of insulin upon ion transport. Biochim Biophys Acta 1983; 737: 1-49.

2. Aulbach F, Simm A, Maier S, Langenfeld H, Walter U, Kersting U, et al. Insulin stimulates the L-type $\mathrm{Ca}^{2+}$ current in rat cardiac myocytes. Cardiovas Res 1998; 42: 113-120.

3. Watanabe T, Ashikaga T, Nishizaki M, Yamawake N, Arita M. Association of insulin with QTc dispersion. Lancet 1997; 350: 1821-1822.

4. Wang Q, Shen J, Splawski I, Atkinson D, Li Z, Robinson JL, et al. SCN5A mutation associated with an inherited cardiac arrhythmia, long QT syndrome. Cell 1995; 80: 805-811.

5. Wang Q, Curran ME, Splawski I, Burn TC, Millholland JM, VanRaay, et al. Positional cloning of a novel potassium channel gene: KVLQT1 mutation cause cardiac arrhythmia. Nat Genet 1996; 12: $17-23$.

6. Curran ME, Splawski I, Timothy KW, Vincent GM, Green ED, Keating MT. A molecular basis for cardiac arrhythmia: HERG mutation causes long QT syndrome. Cell 1995; 80: 795-803.
7. Schwartz PJ, Priori SG, Locati EH, Napolitano C, Cantu F, Towbin JA, et al. Long QT syndrome patients with mutation of the SCN5A and HERG genes have differential responses to $\mathrm{Na}^{+}$channel blocker and to increases in heart rate: Implications for gene-specific therapy. Circulation 1995; 92: 3381-3386.

8. Roden DM, Lazzara R, Rosen M, Schwartz RJ, Towbin J, Vincent $\mathrm{M}$, et al. Multiple mechanisms in the long QT syndrome: Current knowledge, gaps and future directions. Circulation 1996; 94: 19962012.

9. Zareba W, Moss AJ, Schwartz PJ, Vincent M, Robinson JL, Priori $\mathrm{SG}$, et al. Influence of the genotype on the clinical course of the Long-QT syndrome: International Long QT Syndrome Registry Research Group. N Engl J Med 1998; 339: 960-965.

10. Roden DM, Spooner PM. Inherited Long QT syndrome: A paradigm for understanding arrhythmogenesis. J Cardiovasc Electrophysiol 1999; 10: 1664-1683.

11. Towbin JA, Vatta M. The genetic of cardiac arrhythmias. Pacing Clin Electrophysiol 2000; 23: 106-119.

12. Chiang CE, Roden DM. The long QT syndrome: Genetic basis and clinical implications. J Am Coll Cardiol 2000; 36: 1-12.

13. Zhang L, Timothy KW, Vincent GM, Lehmann MH, Fox J, Giuli LC, et al. Spectrum of ST-T-wave patterns and repolarization parameters in congenital long-QT syndrome: ECG findings identify genotypes. Circulation 2000; 102: 2849-2855.

14. Bazzett HC. An analysis of the time relationship of the heart. Heart 1920; 7: 353-370.

15. Hirao H, Shimizu W, Kurita T, Suyama K, Aihara N, Kamakura S, et al. Frequency-dependent electrophysiologic properties of ventricular repolarization in patients with congenital long QT syndrome. $J$ Am Coll Cardiol 1996; 28: 1269-1277.

16. Antzelevitch C, Sicouri S. Clinical relevance of cardiac arrhythmia generated by afterdepolarizations: Role of $\mathrm{M}$ cell in the generation of $\mathrm{U}$ waves, triggered activity and torsade de pointes. J Am Coll Cardiol 1994; 23: 259-277.

17. Malfatto G, Beria G, Sala S, Bonazzi O, Schwartz PJ. Quantitative analysis of $\mathrm{T}$ wave abnormalities and their prognostic implications in the idiopathic long QT syndrome. J Am Coll Cardiol 1994; 23: $296-$ 301.

18. Yan GX, Antzelevitch C. Cellular basis for the normal T wave and the electrocardiographic manifestation of the Long-QT syndrome. Circulation 1998; 98: $1928-1936$.

19. Shimizu W, Antzelevitch C. Cellular and ionic basis for T-wave alternans under Long-QT conditions. Circulation 1999; 99: 1499-1507.

20. Day CP, McComb JM, Cambell RWF. QT dispersion: An indication of arrhythmia in risk patients with long QT interval. Br Heart J 1990; 63: $342-344$.

21. Linker NJ, Colonna P, Kekwick CA, Till J, Camm J, Ward DE. Assessment of QT dispersion in symptomatic patients with congenital long QT syndrome. Am J Cardiol 1992; 69: 634-638.

22. Priori SG, Napolitano C, Diehl L, Schwartz PJ. Dispersion of the QT interval: A marker of therapeutic efficacy in the idiopathic long QT syndrome. Circulation 1994; 89: 1681-1689.

23. Antzelevitch C, Shimizu W, Yan GX, Sicouri S. Cellular basis for QT dispersion. J Electrocardiol 1998; 30: 168-175.

24. La Manna VR, Ferrier GF. Electrophysiological effects of insulin on normal and depressed cardiac tissue. Am J Physiol 1981; 240: H636-H644.

25. Eckei J, Reinauer H. Modulation of transmembrane potential of isolated cardiac myocytes by insulin and isoproterenol. Am J Physiol 1990; 2592: H554-H559.

26. Hansen PS, Buhagiar KA, Gray DF, Rasmussen HH. Voltage-dependent stimulation of the $\mathrm{Na}(+)-(\mathrm{K}+)$ pump by insulin in rabbit cardiac myocytes. Am J Physiol (Cell Physiol) 2000; 278: C546-C553.

27. Priori SG, Napolitano C, Schwartz PJ. Low penetrance in the long QT syndrome: Clinical impact. Circulation 1999; 99: 529-533.

28. Napolitano C, Schwartz PJ, Brown AM, Ronchetti E, Bianchi L, Pinnavaia A, et al. Evidence for a cardiac ion channel mutation underlying drug-induced QT prolongation and life-threatening arrhythmias. J Cardiovasc Electrophysiol 2000; 11: 691-696.

29. Moss AJ, Zareba W, Benhorin J, Locati E, Hall WJ, Robinson JL, et al. ECG T-wave patterns in genetically distinct forms of the hereditary long QT syndrome. Circulation 1995; 92: 2929-2934. 